\title{
openheart Adherence to process of care quality indicators after percutaneous coronary intervention in Ontario, Canada: a retrospective observational cohort study
}

Andrew Czarnecki, ${ }^{1,2}$ Treesa J Prasad, ${ }^{2}$ Julie Wang, ${ }^{2}$ Harindra C Wijeysundera, ${ }^{1,2,3}$ Asim N Cheema, ${ }^{3,4}$ Vladimír Džavík, ${ }^{3,5}$ Madhu K Natarajan, ${ }^{6}$ Chris S Simpson, ${ }^{7}$ Derek Y So, ${ }^{8}$ Jaffer Syed, ${ }^{9}$ Jack V Tu, ${ }^{1,2,3}$ Dennis T Ko ${ }^{1,2,3}$

To cite: Czarnecki $A$, Prasad TJ, Wang J, et al. Adherence to process of care quality indicators after percutaneous coronary intervention in Ontario, Canada: a retrospective observational cohort study. Open Heart 2015;2:e000200. doi:10.1136/openhrt-2014000200

Received 25 September 2014 Revised 8 January 2015 Accepted 23 January 2015

\section{CrossMark}

For numbered affiliations see end of article.

Correspondence to Dr Dennis T Ko; dennis.ko@ices.on.ca

\section{ABSTRACT}

Background: Public reporting of percutaneous coronary intervention (PCl) outcomes has been established in many jurisdictions to ensure optimal delivery of care. The majority of $\mathrm{PCl}$ report cards examine in-hospital mortality, but relatively little is known regarding the adherence to processes of care. Methods: A modified Delphi panel comprising cardiovascular experts was assembled to develop a set of $\mathrm{PCl}$ quality indicators. Indicators such as prescription of aspirin, dual antiplatelet therapy, statins and smoking cessation counselling were identified to represent high-quality $\mathrm{PCl}$ care. Chart abstraction was performed at $13 \mathrm{PCl}$ hospitals in Ontario, Canada from 2009 to 2010 with at least $200 \mathrm{PCl}$ patients randomly selected from each hospital.

Results: Our study sample included 3041 patients, of whom $18 \%$ had stable coronary artery disease (CAD) and $82 \%$ had an acute coronary syndrome (ACS). Their mean age was $63 \pm 12.4$ years and $29 \%$ of patients were female. Prior to $\mathrm{PCl}, 89 \%$ were prescribed aspirin, and after PCI 98.7\% were prescribed aspirin, $95.1 \%$ were prescribed dual antiplatelet therapy for 12 months after drug-eluting stents, and $94.9 \%$ were prescribed statins. The lowest performing quality indicator was smoking cessation counselling, observed in only $42 \%$ of current and past smokers ( $18 \%$ in patients with stable CAD and $47 \%$ in ACS).

Conclusions: Our study demonstrates high levels of adherence to most quality indicators for patients undergoing $\mathrm{PCl}$ procedures in Ontario. In conclusion, smoking cessation counselling was not consistently performed across hospitals and represents an opportunity for future quality improvement efforts.

\section{INTRODUCTION}

The growing emphasis on accountability in the healthcare system has increased the demands to ensure delivery of quality care. ${ }^{1}$ Optimising the performance of percutaneous coronary intervention (PCI) procedures has been the focus of many healthcare

\section{KEY MESSAGES}

What is already known about this subject?

- Many jurisdictions publicly report in-hospital mortality rates as the primary measure to determine the quality of percutaneous coronary intervention ( $\mathrm{PCl}$ ) procedures. However, a focus on mortality as the only indicator of quality potentially ignores other important aspects of $\mathrm{PCl}$ and little is known regarding the adherence to other important processes of care which reflect quality.

What does this study add?

- We performed a detailed chart abstraction study across Ontario, Canada to measure adherence to previously published quality indicators and found that most centres have achieved high levels of adherence to quality indicators. However, smoking cessation counselling remains underutilised.

How might this impact on clinical practice?

- Given the potentially large impact on public health, further quality improvement efforts should focus on providing optimal levels of smoking cessation counselling.

systems as a large number of patients with stable coronary artery disease (CAD) and acute coronary syndrome (ACS) are being treated with PCI. Many jurisdictions have publicly reported in-hospital mortality rates as the primary measure to determine the quality of PCI procedures. ${ }^{2-4}$ However, a focus on mortality as the only indicator of quality potentially ignores other important aspects of PCI. ${ }^{5}$ For example, it is clear that the quality of PCI is suboptimal if a patient is not prescribed dual antiplatelet therapy after the procedure, even if the patient survives.

Our group has previously assembled a modified Delphi panel comprising general cardiologists, interventional cardiologists and 
outcome researchers, and developed a list of process of care PCI indicators supported by the Canadian Cardiovascular Society and the Canadian Association of Interventional Cardiology that are applicable to routine clinical practice. ${ }^{5}$ The main focus of our current study was to measure the adherence rate of quality indicators in patients treated with PCI, which allowed us to gain insights into the quality of care and to identify deficiencies in contemporary clinical practice.

\section{METHODS}

\section{System context}

Approximately 50000 cardiac catheterisations and 20000 PCI procedures are performed annually in Ontario, Canada. ${ }^{6} 7$ At the time of the study, Ontario had 14 hospitals with the capability to perform PCI procedures. Of the 14 eligible hospitals, 13 participated in the chart abstraction study.

\section{Ontario PCI chart abstraction study}

A province-wide chart abstraction study was conducted by nurse abstractors with experience in clinical cardiology deployed at each hospital to gather relevant information. This was necessary because many processes of care and outcome measures were not available using existing provincial administrative or clinical databases. Each abstractor underwent comprehensive training in data elements and data definition prior to abstraction. Data reliability was examined by reabstraction of randomly selected charts and each abstractor demonstrated a high rate for accuracy and completeness.

A target study sample of at least 200 PCI patients from larger PCI centres was selected in order to obtain a representative population-based sample of patients undergoing PCI. In two hospitals that have lower PCI volumes of less than 500 procedures per year, we sampled approximately $30 \%$ of their annual volume in order to avoid oversampling. We used the Canadian Institutes for Health Information to first identify patients who had PCI procedures in the province, and then selected a random sample at each hospital using computergenerated algorithms.

\section{Study sample}

All patients who underwent PCI between 2009 and 2010 were eligible for inclusion. The proportion of patients with stable $\mathrm{CAD}$ and ACS was selected at random in each hospital. Patients who had received prior PCI were excluded because our aim was to examine the quality of care in an inception cohort of patients undergoing their first interventional procedure.

\section{Outcomes}

Our main outcomes of interest were process of care indicators as developed by the Canadian quality indicators panel for PCI. ${ }^{5}$ These indicators included: aspirin prior to PCI, renal function assessment prior to PCI, cardiac biomarker measurement after PCI, discharge medication prescriptions (aspirin, clopidogrel, statins) and smoking cessation counselling. We also examined outcome indicators that included: mortality, emergent coronary revascularisation and in-hospital complications (myocardial infarction, stroke or transient ischaemic attack, bleeding or access site complications, need for vascular repair and blood transfusion). Detailed definitions of each indicator have been previously published elsewhere. ${ }^{5}$ To determine out-of-hospital mortality, the chart abstraction clinical data were linked to the Ontario Registered Persons Database using encrypted patient identifiers to protect patient confidentiality.

\section{Statistical analysis}

Baseline characteristics and process and outcome indicators were presented as overall rates and stratified by clinical status (stable CAD or ACS). Patients with ACS included those who had unstable angina, non-STsegment elevation myocardial infarction and ST-segment elevation myocardial infarction. Process and outcome indicators were further divided at the hospital level to examine potential variation across the province. All process indicators are presented without adjustment for patient characteristics, as they should be performed in nearly all patients, regardless of patient characteristics. Baseline characteristics and outcome variables were presented as means with SDs or ranges (where appropriate). Differences between groups were analysed using the Student $t$ test for continuous variables while $\chi^{2}$ were used for categorical variables. A two-tailed value of $p<0.05$ was considered statistically significant. To better assess hospital variation of quality indicators and process-outcome relationship, we generated a composite adherence score for each patient by summing the total number of indicators performed divided by the total number of eligible indicators. The individual patient scores were averaged at each hospital to generate a mean composite score for each institution. Analyses were performed with SAS V.9.3 (SAS Institute Inc, Cary, North Carolina, USA).

\section{RESULTS \\ Baseline characteristics}

Overall, 3041 patients were included in the final study cohort. The mean age was 64 years; $29 \%$ of patients were female, $25 \%$ of patients had diabetes mellitus, and $16 \%$ had a history of myocardial infarction. The majority of patients (82\%) received PCI due to an ACS, and $18 \%$, due to stable CAD (table 1 ).

Patients who received PCI because of stable CAD were older than patients who received PCI because of ACS (66.3 vs 62.8 years; $\mathrm{p}<0.001$ ). Patients with stable CAD also had more cardiac risk factors including hypertension, diabetes, hyperlipidaemia, a history of smoking and recent heart failure symptoms compared with patients with ACS. On the other hand, patients who 
Table 1 Demographic and clinical characteristics

\begin{tabular}{|c|c|c|c|c|}
\hline Characteristics & $\begin{array}{l}\text { Overall } \\
(n=3041)\end{array}$ & $\begin{array}{l}\text { Stable CAD } \\
(n=542)\end{array}$ & $\begin{array}{l}\text { ACS } \\
(n=2499)\end{array}$ & p Value* \\
\hline \multicolumn{5}{|l|}{ Demographics (\%) } \\
\hline Age \pm mean, SD & $63.5 \pm 12.4$ & $66.3 \pm 10.9$ & $62.8 \pm 12.6$ & $<0.001$ \\
\hline Female & $876(28.8 \%)$ & $154(28.4 \%)$ & $722(28.9 \%)$ & 0.824 \\
\hline \multicolumn{5}{|l|}{ Cardiac risk factors (\%) } \\
\hline Hypertension & $1812(59.6 \%)$ & $396(73.1 \%)$ & $1416(56.7 \%)$ & $<0.001$ \\
\hline Diabetes & $755(24.8 \%)$ & $164(30.3 \%)$ & $591(23.6 \%)$ & 0.001 \\
\hline Hyperlipidaemia & $1677(55.1 \%)$ & 407 (75.1\%) & $1270(50.8 \%)$ & $<0.001$ \\
\hline Current smoker & $878(28.9 \%)$ & $72(13.3 \%)$ & $806(32.3 \%)$ & $<0.001$ \\
\hline Former smoker & $769(25.3 \%)$ & $190(35.1 \%)$ & $579(23.2 \%)$ & $<0.001$ \\
\hline \multicolumn{5}{|c|}{ Clinical characteristics 2 weeks prior to procedure (\%) } \\
\hline Heart failure & $560(18.4 \%)$ & $152(28.0 \%)$ & $408(16.3 \%)$ & $<0.001$ \\
\hline \multicolumn{5}{|l|}{ CCS class for angina } \\
\hline Class 0 & $484(15.9 \%)$ & $57(10.5 \%)$ & $427(17.1 \%)$ & $<0.001$ \\
\hline Class I & $116(3.8 \%)$ & $98(18.1 \%)$ & $18(0.7 \%)$ & \\
\hline Class II & $410(13.5 \%)$ & $216(39.9 \%)$ & $194(7.8 \%)$ & \\
\hline Class III & $671(22.1 \%)$ & $151(27.9 \%)$ & $520(20.8 \%)$ & \\
\hline Class IV & $1310(43.1 \%)$ & $8(1.5 \%)$ & $1302(52.1 \%)$ & \\
\hline \multicolumn{5}{|l|}{ Medical and cardiac history (\%) } \\
\hline Heart failure & $99(3.3 \%)$ & $21(3.9 \%)$ & $78(3.1 \%)$ & 0.37 \\
\hline Myocardial infarction & $471(15.5 \%)$ & $83(15.3 \%)$ & $388(15.5 \%)$ & 0.901 \\
\hline Coronary artery bypass grafting surgery & 255 (8.4\%) & $71(13.1 \%)$ & $184(7.4 \%)$ & $<0.001$ \\
\hline Cerebrovascular disease & $191(6.3 \%)$ & $33(6.1 \%)$ & $158(6.3 \%)$ & 0.839 \\
\hline Peripheral vascular disease & $175(5.8 \%)$ & $42(7.7 \%)$ & $133(5.3 \%)$ & 0.028 \\
\hline Chronic obstructive pulmonary disease & $204(6.7 \%)$ & $29(5.4 \%)$ & $175(7.0 \%)$ & 0.163 \\
\hline Chronic renal disease & $103(3.4 \%)$ & $21(3.9 \%)$ & $82(3.3 \%)$ & 0.489 \\
\hline Cancer & $213(7.0 \%)$ & $35(6.5 \%)$ & $178(7.1 \%)$ & 0.582 \\
\hline
\end{tabular}

${ }^{*} p$ Value compares characteristics between patients with stable CAD and ACS.

ACS, acute coronary syndrome; CAD, coronary artery disease; CCS, Canadian Cardiovascular Society.

received PCI for an ACS had significantly higher rates of current smoking (32.3\% vs $13.3 \%$; $\mathrm{p}<0.001$; table 1 ).

\section{Process of care quality indicators}

High rates of adherence to quality indicators in patients undergoing PCI for stable CAD and ACS were observed (table 2). The overall cohort had a mean composite adherence score of $89 \%$, while patients with stable CAD and ACS had $87 \%$ and $90 \%$, respectively $(\mathrm{p}=0.003$ for stable CAD vs ACS). Overall, $89 \%$ were prescribed aspirin prior to PCI, whereas $98.7 \%$ were prescribed aspirin after PCI, 97\% were prescribed dual antiplatelet therapy for 1 month after bare metal stents, $95.1 \%$ were prescribed dual antiplatelet therapy for 12 months after drug-eluting stents, and $94.9 \%$ were prescribed statins. The lowest performing quality indicator was smoking cessation counselling, which was observed in only $41.9 \%$ of current and past smokers (18\% in stable CAD and $47 \%$ in ACS; $p<0.001$ ), and in $64.5 \%$ of current smokers (39\% in stable CAD and 67\% in ACS; $\mathrm{p}<0.001$ ).

Although most hospitals were adherent to all quality indicators, a few exceptions were noted. In one hospital, aspirin was only administrated to $14.1 \%$ of patients prior to PCI. Wide variations were also noted for smoking cessation counselling. For patients who were current or past smokers, counselling ranged from a low of $7.7 \%$ to a high of $86.3 \%$. For patients who were current smokers, counselling ranged from $24.6 \%$ to $96.1 \%$. The use of cardiac biomarker measures after PCI ranged from $54.4 \%$ to $100 \%$. Overall, the composite indicator score ranged from $79 \%$ to $97 \%(\mathrm{p}<0.001)$ across Ontario hospitals (table 2).

\section{Outcome indicators}

Mortality and other outcomes of interest after PCI procedures are shown in table 3. Among patients with stable CAD, 30-day mortality was $1.3 \%$ and 1-year mortality was $2.6 \%$. Among patients with an ACS, 30-day mortality was significantly higher at $3.2 \%$ and 1-year mortality was $5.9 \%$. There was variation in postprocedural outcomes across Ontario that 30-day mortality ranged from $0 \%$ to $7.8 \%$, while 1 -year mortality ranged from $2.0 \%$ to $11.4 \%$. We also attempted to explore the relationship between quality of care and outcomes. Figure 1 shows that although most PCI centres had relatively high adherence to quality indicators, significant variation in mortality was observed at 30 days after PCI.

Overall, complications were also relatively infrequent after PCI with an emergency bypass rate of $1.2 \%$, need for a blood transfusion rate of $1.0 \%$, major bleeding or access site complication rate of $1.6 \%$, and vascular repair rate of $0.8 \%$. There was also a variation in the 
Table 2 Process of care indicators of $\mathrm{PCl}$

\begin{tabular}{|c|c|c|c|c|c|c|c|}
\hline \multirow[b]{2}{*}{ Quality indicators } & \multicolumn{2}{|l|}{ Overall } & \multicolumn{2}{|l|}{ Stable CAD } & \multicolumn{2}{|l|}{ ACS } & \multirow[b]{2}{*}{ p Value* } \\
\hline & $\begin{array}{l}\text { Number of eligible } \\
\text { patients (\% treated) }\end{array}$ & $\begin{array}{l}\text { Hospital } \\
\text { range (\%) }\end{array}$ & $\begin{array}{l}\text { Number of eligible } \\
\text { patients (\% treated) }\end{array}$ & $\begin{array}{l}\text { Hospital } \\
\text { range (\%) }\end{array}$ & $\begin{array}{l}\text { Number of eligible } \\
\text { patients (\% treated) }\end{array}$ & $\begin{array}{l}\text { Hospital } \\
\text { range (\%) }\end{array}$ & \\
\hline \multicolumn{8}{|l|}{ Preprocedure process of care } \\
\hline Aspirin before $\mathrm{PCl}$ & $3020(89.0 \%)$ & $14.1-100$ & $539(95.9 \%)$ & $8.3-100$ & $2481(87.5 \%)$ & $14.5-100$ & $<0.001$ \\
\hline $\begin{array}{l}\text { Renal function assessment } \\
\text { before } \mathrm{PCl}\end{array}$ & $3011(94.5 \%)$ & $84.0-100$ & $542(96.7 \%)$ & $84.6-100$ & $2469(94.0 \%)$ & $80.0-100$ & 0.012 \\
\hline \multicolumn{8}{|c|}{ Postprocedural process of care } \\
\hline $\begin{array}{l}\text { Cardiac biomarker } \\
\text { measurement after } \mathrm{PCl}\end{array}$ & 2919 (90.5\%) & $54.4-100$ & $533(86.7 \%)$ & $33.3-100$ & $2386(91.4 \%)$ & $61.4-100$ & $<0.001$ \\
\hline \multicolumn{8}{|c|}{ Processes of care at hospital discharge } \\
\hline Aspirin & 2968 (98.7\%) & $93.5-100$ & $536(99.4 \%)$ & $81.8-100$ & $2432(98.5 \%)$ & $91.8-100$ & 0.08 \\
\hline $\begin{array}{l}>1 \text { month dual antiplatelet } \\
\text { therapy for BMS }\end{array}$ & $1698(97.0 \%)$ & $89.1-100$ & $225(98.7 \%)$ & $94.6-100$ & $1473(96.7 \%)$ & $88.9-100$ & 0.115 \\
\hline $\begin{array}{l}>12 \text { month dual antiplatelet } \\
\text { therapy for DES }\end{array}$ & $1065(95.1 \%)$ & $76.1-100$ & $256(97.3 \%)$ & $75.0-100$ & $809(94.4 \%)$ & $75.0-100$ & 0.067 \\
\hline Statin therapy & 2963 (94.9\%) & $84.1-100$ & $533(90.1 \%)$ & $74.1-100$ & $2430(96.0 \%)$ & $82.0-100$ & $<0.001$ \\
\hline $\begin{array}{l}\text { Smoking cessation advice/ } \\
\text { counselling/therapy }\end{array}$ & $1438(41.9 \%)$ & 7.7-86.3 & $251(17.9 \%)$ & $0-100$ & $1187(46.9 \%)$ & $13.4-86.1$ & $<0.001$ \\
\hline $\begin{array}{l}\text { Mean Composite Adherence } \\
\text { Score }(\text { mean } \% \pm S D) \dagger\end{array}$ & \multicolumn{2}{|c|}{$89 \% \pm 14 \%$} & \multicolumn{2}{|c|}{$87 \% \pm 14 \%$} & \multicolumn{2}{|c|}{$90 \% \pm 14 \%$} & 0.003 \\
\hline
\end{tabular}


Table 3 Outcome indicators ${ }^{*}$

\begin{tabular}{|c|c|c|c|c|c|c|c|}
\hline \multirow[b]{2}{*}{ Quality indicator } & \multicolumn{2}{|c|}{ Overall ( $\mathrm{N}=\mathbf{3 0 4 1})$} & \multicolumn{2}{|c|}{ Stable CAD (N=542) } & \multicolumn{2}{|c|}{ ACS $(\mathrm{N}=2499)$} & \multirow[b]{2}{*}{$\begin{array}{l}\text { p } \\
\text { Value } †\end{array}$} \\
\hline & n (\%) & $\begin{array}{l}\text { Hospital } \\
\text { range (\%) }\end{array}$ & n (\%) & $\begin{array}{l}\text { Hospital } \\
\text { range (\%) }\end{array}$ & n (\%) & $\begin{array}{l}\text { Hospital } \\
\text { range (\%) }\end{array}$ & \\
\hline \multicolumn{8}{|l|}{ Mortality } \\
\hline In-hospital & $62(2.0 \%)$ & $0-6.2$ & $\leq 5$ & $0-28.6$ & $58(2.3 \%)$ & $0-5.4$ & 0.018 \\
\hline 30 days & $86(2.8 \%)$ & $0-7.8$ & $7(1.3 \%)$ & $0-42.9$ & 79 (3.2\%) & $0-6.5$ & 0.017 \\
\hline 1 year & $162(5.3 \%)$ & $2.0-11.4$ & $14(2.6 \%)$ & $0-42.9$ & $148(5.9 \%)$ & $2.2-10.2$ & 0.002 \\
\hline Emergency CABG & 35 (1.2\%) & $0-4.8$ & $\leq 5$ & NA & $34(1.4 \%)$ & $0-4.8$ & 0.02 \\
\hline Emergency repeat $\mathrm{PCl}$ & $35(1.2 \%)$ & $0-4.5$ & 0 & 0 & $35(1.4 \%)$ & $0-4.9$ & 0.006 \\
\hline $\begin{array}{l}\text { Renal failure requiring } \\
\text { dialysis }\end{array}$ & $6(0.2 \%)$ & $0-1.0$ & $\leq 5$ & NA & $\leq 5$ & NA & 0.941 \\
\hline $\begin{array}{l}\text { Stroke or transient } \\
\text { ischaemic attack }\end{array}$ & $15(0.5 \%)$ & $0-1.4$ & 0 & 0 & $15(0.6 \%)$ & $0-1.5$ & 0.071 \\
\hline Myocardial infarction & $34(1.1 \%)$ & $0-3.5$ & $\leq 5$ & NA & $33(1.3 \%)$ & $0-3.6$ & 0.023 \\
\hline $\begin{array}{l}\text { Intra-aortic balloon pump } \\
\text { insertion }\end{array}$ & 99 (3.3\%) & $0-10.1$ & $\leq 5$ & NA & $97(3.9 \%)$ & $0-10.3$ & $<0.001$ \\
\hline $\begin{array}{l}\text { Bleeding/access site } \\
\text { complications }\end{array}$ & $48(1.6 \%)$ & $0-6.1$ & $7(1.3 \%)$ & $0-14.3$ & $41(1.6 \%)$ & $0-5.8$ & 0.554 \\
\hline Vascular repair & $25(0.8 \%)$ & $0-3.2$ & $\leq 5$ & NA & $23(0.9 \%)$ & $0-4.1$ & 0.198 \\
\hline Blood transfusion & $29(1.0 \%)$ & $0-3.2$ & 0 & 0 & $29(1.2 \%)$ & $0-3.3$ & 0.012 \\
\hline Thrombocytopaenia & $8(0.3 \%)$ & $0-1.5$ & 0 & 0 & $8(0.3 \%)$ & $0-1.6$ & 0.187 \\
\hline
\end{tabular}

proportion of patients experiencing complications across hospitals. For example, bleeding or access site complications varied from $0 \%$ to $6.1 \%$.

\section{DISCUSSION}

Our study extends prior knowledge in the area of PCI public reporting by examining the adherence of quality indicators in contemporary practice. First, we demonstrated high levels of adherence to most process of care indicators that were deemed important to optimise PCI outcomes. Second, smoking cessation counselling was the lowest performing quality indicator, highlighting an important area for future quality improvement efforts.
Finally, adverse outcomes after PCI were rare but varied significantly after PCI across hospitals.

Quality indicators are processes of care in which the evidence is so strong that the failure to perform such actions reduces the likelihood of optimising patient outcomes. ${ }^{8}$ Quantifying adherence to indicators can therefore serve as a direct measure of the quality of care and serve as a foundation for quality improvement. ${ }^{10}$ Although our study was performed in Canada, we believe our study generated important insights into care delivery which are broadly applicable. First, we demonstrated the feasibility of using PCI quality indicators to assess quality of care in routine clinical use. Our data also created a potential benchmark of these indicators
Figure 1 Relationship between composite adherence score and 30-day mortality after percutaneous coronary intervention (PCI). Thirty-day mortality after $\mathrm{PCl}$ on the y-axis was plotted against the mean composite adherence score for quality indicators on the $\mathrm{x}$-axis. Each dot represented a single PCl hospital.

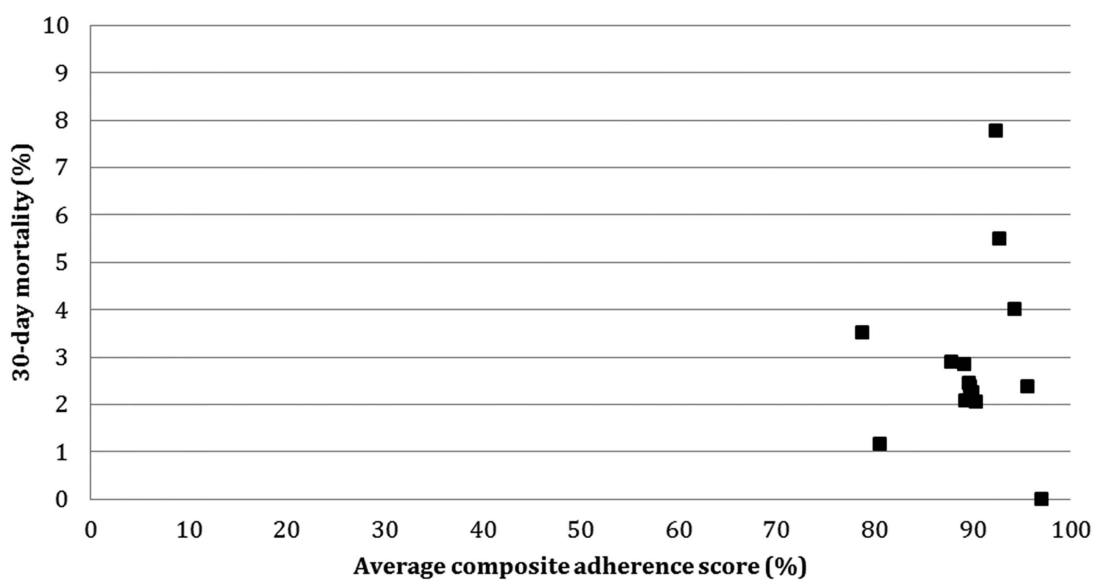


that could be used in other jurisdictions. Finally, despite the widespread evidence supporting these quality indicators, we believe that there remains significant variation and areas for future improvement in most practice environments.

We demonstrated for the first time that hospitals that perform PCI in Ontario have high adherence to most quality indicators. This insight that Ontario hospitals are providing good quality of care in PCI is reassuring for patients, physicians and health policymakers. It is also important for the planning of future quality improvement efforts because it may allow Ontario hospitals to focus on deficient areas, rather than devoting additional resources to processes that are already at optimal levels. One potential area for future quality improvement initiatives is smoking cessation counselling. We found that smoking cessation counselling was performed in just $42 \%$ of the PCI patients who were current or previous smokers. Our current observation is consistent with a prior study demonstrating that about one in two patients with acute myocardial infarction were offered smoking cessation counselling in Ontario. ${ }^{11}$ More importantly, the study found that counselled smokers had a $37 \%$ lower risk of mortality than those not counselled, even taking into account confounding factors. In contrast, the Get with the Guidelines initiatives have been successful in increasing smoking cessation counselling from $68 \%$ to $97 \%$ between 2002 and 2007 in the USA. ${ }^{12}$ Thus, a coordinated quality improvement effort aimed at smoking cessation should be an important priority in the treatment of patients with cardiac symptoms or disease in Canada.

In our study, we also captured outcomes of PCI that were not possible in traditional report cards that utilise administrative data such as access site complication, emergency coronary revascularisation, vascular repair or transfusion. Most of these known adverse events of PCI occurred rarely in Ontario. We observed 30-day mortality rate of $2.8 \%$ in our study cohort, which was in line with other reports in different jurisdictions. ${ }^{2-4}{ }^{13-15}$ Interestingly, despite the wide variation in mortality at the hospital level, we did not observe a correlation in the composite adherence score in the explorative analysis. However, we were unable to perform a formal evaluation of the process-outcome relationship and account for the difference in case mix because of the small number of PCI in each hospital. However, lack of a strong relationship between quality of care and outcomes has been previously demonstrated in patients hospitalised with acute myocardial infarction and heart failure. ${ }^{16}{ }^{17}$ For example, Bradley et $a l^{17}$ demonstrated that only $6 \%$ of interhospital risk-adjusted variation in 30-day mortality for myocardial infarction was explained by differences in process measure adherence. Future study is needed to evaluate the extent to which processes of care in PCI are associated with patient outcomes.

Our data represent one of the first studies that utilises high-quality clinical data to examine the quality indicators associated with PCI; however, there are several limitations that merit discussion. First, we were not able to formally evaluate the relationship between processes of care and risk-adjusted models, given the small number of events. Second, we evaluated approximately 200 patients per hospital to assess quality of care of PCI empirically on the basis that this number could be indicative of quality of care at the hospital level. This decision was made because there is no widely accepted method of determining the minimal number of patients to assess quality of care at the hospital level. Third, although our study evaluated the adherence to quality indicators and outcomes related to PCI procedures, we did not evaluate the appropriateness of the procedures. Given the fact that adverse events rarely occur after PCI for patients with stable $\mathrm{CAD}$, it is possible that examining the appropriateness and the procedure indication may be most indicative of the quality of care. Furthermore, as new evidence is adopted, the assessment of procedure quality must evolve over time and some of the included indicators, such as the routine measurement of biomarkers post-PCI, may not be as relevant to practice today. In addition, we defined the use of at least 1 month of dual anti-platelet therapy for patients with ACS and bare-metal stent implantation as a quality indicator to reflect recommendations at the time of the study. However, we acknowledge that current recommendations suggest 12 months of therapy for these patients. We also did not evaluate some process of care measures, such as door-to-balloon times in patients with ST-segment elevation myocardial infarction because these data were not captured in our data set. Finally, in our randomly selected study sample of PCI patients, the proportion of patients with stable CAD was only $18 \%$, which may be lower than that for other PCI practices.

In summary, our study demonstrates high levels of adherence to most quality indicators for patients undergoing PCI procedures in Ontario. Similarly, PCI complication outcomes were on par with accepted standards, reflecting an overall high quality of care. However, smoking cessation counselling was not performed consistently, and should represent a focus for future quality improvement efforts.

Author affiliations

${ }^{1}$ Schulich Heart Centre, Sunnybrook Health Sciences Centre, Toronto, Ontario, Canada

${ }^{2}$ Institute for Clinical Evaluative Sciences (ICES), Toronto, Ontario, Canada ${ }^{3}$ Department of Medicine, University of Toronto, Toronto, Ontario, Canada

${ }^{4}$ Division of Cardiology, St. Michael's Hospital, Toronto, Ontario, Canada

${ }^{5}$ Peter Munk Cardiac Centre, University Health Network, Toronto, Ontario,

Canada

${ }^{6}$ Hamilton General Hospital, McMaster University, Hamilton, Ontario, Canada ${ }^{7}$ Department of Medicine, Queen's University, Kingston, Ontario, Canada

${ }^{8}$ Division of Cardiology, University of Ottawa Heart Institute, Ottawa, Ontario, Canada

${ }^{9}$ Division of Cardiology, Western University, London, Ontario, Canada

Funding This was supported by a Canadian Institutes of Health Research (CIHR) operating grant (MOP-102487). HCW is supported by a Distinguished Clinical Scientist Award from the Heart and Stroke Foundation of Canada. JVT 
is supported by a Canada Research Chair in Health Services Research and a Career Investigator Awards from the Heart and Stroke Foundation, Ontario Provincial Office. DTK is supported by a Clinician-Scientist Award from the Heart and Stroke Foundation, Ontario Provincial Office.

Competing interests None declared.

Ethics approval Research ethics boards at each participating hospital.

Provenance and peer review Not commissioned; externally peer reviewed.

Open Access This is an Open Access article distributed in accordance with the Creative Commons Attribution Non Commercial (CC BY-NC 4.0) license, which permits others to distribute, remix, adapt, build upon this work noncommercially, and license their derivative works on different terms, provided the original work is properly cited and the use is non-commercial. See: http:// creativecommons.org/licenses/by-nc/4.0/

\section{REFERENCES}

1. Levine GN, Bates ER, Blankenship JC, et al. 2011 ACCF/AHA/SCA Guideline for Percutaneous Coronary Intervention: a report of the American College of Cardiology Foundation/American Heart Association Task Force on Practice Guidelines and the Society for Cardiovascular Angiography and Interventions. Circulation 2011;124 e574-651.

2. Adult Percutaneous Coronary Intervention in the Commonwealth of Massachussetts. Fiscal Year 2011 Report. http://www.massdac.org/ wp-content/uploads/PCI-FY2011.pdf (accessed 6 Jul 2014).

3. Percutaneous Coronary Interventions (PCI) in New York State 20072009. New York State Department of Health. https://www.health.ny. gov/statistics/diseases/cardiovascular/docs/pci_2007-2009.pdf (accessed 6 Jul 2014).

4. Report on adult percutaneous coronary interventions $(\mathrm{PCl})$ in Ontario. October 2008-September 2011. Cardiac Care Network of Ontario. http://www.ccn.on.ca/ccn_public/uploadfiles/files/Provincial_ PCI_Report_FINAL.pdf (accessed 6 Jul 2014).

5. Ko DT, Wijeysundera $\mathrm{HC}$, Zhu X, et al. Canadian quality indicators for percutaneous coronary interventions. Can J Cardiol 2008;24:899-903.

6. Ko DT, Tu JV, Samadashvili Z, et al. Temporal trends in the use of percutaneous coronary intervention and coronary artery bypass surgery in New York State and Ontario. Circulation 2010;121:2635-44.

7. Ko DT, Guo H, Wijeysundera HC, et al. Assessing the association of appropriateness of coronary revascularization and clinical outcomes for patients with stable coronary artery disease. J Am Coll Cardiol 2012;60:1876-84.

8. Gibbons RJ, Smith S, Antman E; American College of Cardiology; American Heart Association. American College of Cardiology/ American Heart Association clinical practice guidelines: Part I: where do they come from? Circulation 2003;107:2979-86.

9. Gibbons RJ, Smith SC Jr, Antman E; American College of Cardiology; American Heart Association. American College of Cardiology/American Heart Association clinical practice guidelines: Part II: evolutionary changes in a continuous quality improvement project. Circulation 2003;107:3101-7.

10. Spertus JA, Eagle KA, Krumholz HM, et al. American College of Cardiology and American Heart Association methodology for the selection and creation of performance measures for quantifying the quality of cardiovascular care. Circulation 2005;111:1703-12.

11. Van Spall HG, Chong A, Tu JV. Inpatient smoking-cessation counseling and all-cause mortality in patients with acute myocardial infarction. Am Heart J 2007;154:213-20.

12. Huang $\mathrm{PH}$, Kim CX, Lerman $\mathrm{A}$, et al. Trends in smoking cessation counseling: experience from American Heart Association-get with the guidelines. Clin Cardiol 2012;35:396-403.

13. Aggarwal A, Dai D, Rumsfeld JS, et al; American College of Cardiology National Cardiovascular Data Registry. Incidence and predictors of stroke associated with percutaneous coronary intervention. Am J Cardiol 2009;104:349-53.

14. Applegate RJ, Sacrinty MT, Kutcher MA, et al. Trends in vascular complications after diagnostic cardiac catheterization and percutaneous coronary intervention via the femoral artery, 1998 to 2007. J Am Coll Cardiol Interv 2008;1:317-26.

15. Peterson ED, Dai D, DeLong ER, et al. Contemporary mortality risk prediction for percutaneous coronary intervention: results from 588,398 procedures in the National Cardiovascular Data Registry. J Am Coll Cardiol 2010;55:1923-32.

16. Fonarow GC, Abraham WT, Albert NM, et al. Association between performance measures and clinical outcomes for patients hospitalized with heart failure. JAMA 2007;297:61-70.

17. Bradley EH, Herrin J, Elbel B, et al. Hospital quality for acute myocardial infarction: correlation among process measures and relationship with short-term mortality. JAMA 2006;296:72-8. 